This item was submitted to Loughborough's Research Repository by the author.

Items in Figshare are protected by copyright, with all rights reserved, unless otherwise indicated.

\title{
An analysis of climate change policy-making and implementation in China
}

PLEASE CITE THE PUBLISHED VERSION

http://www.emeraldinsight.com/journals.htm?issn=1756-8692

\section{PUBLISHER}

(C) Emerald

\section{VERSION}

AM (Accepted Manuscript)

\section{LICENCE}

CC BY-NC-ND 4.0

\section{REPOSITORY RECORD}

Chmutina, Ksenia, Jie Zhu, and Saffa Riffat. 2019. "An Analysis of Climate Change Policy-making and Implementation in China”. figshare. https://hdl.handle.net/2134/10258. 
This item was submitted to Loughborough's Institutional Repository (https://dspace.lboro.ac.uk/) by the author and is made available under the following Creative Commons Licence conditions.

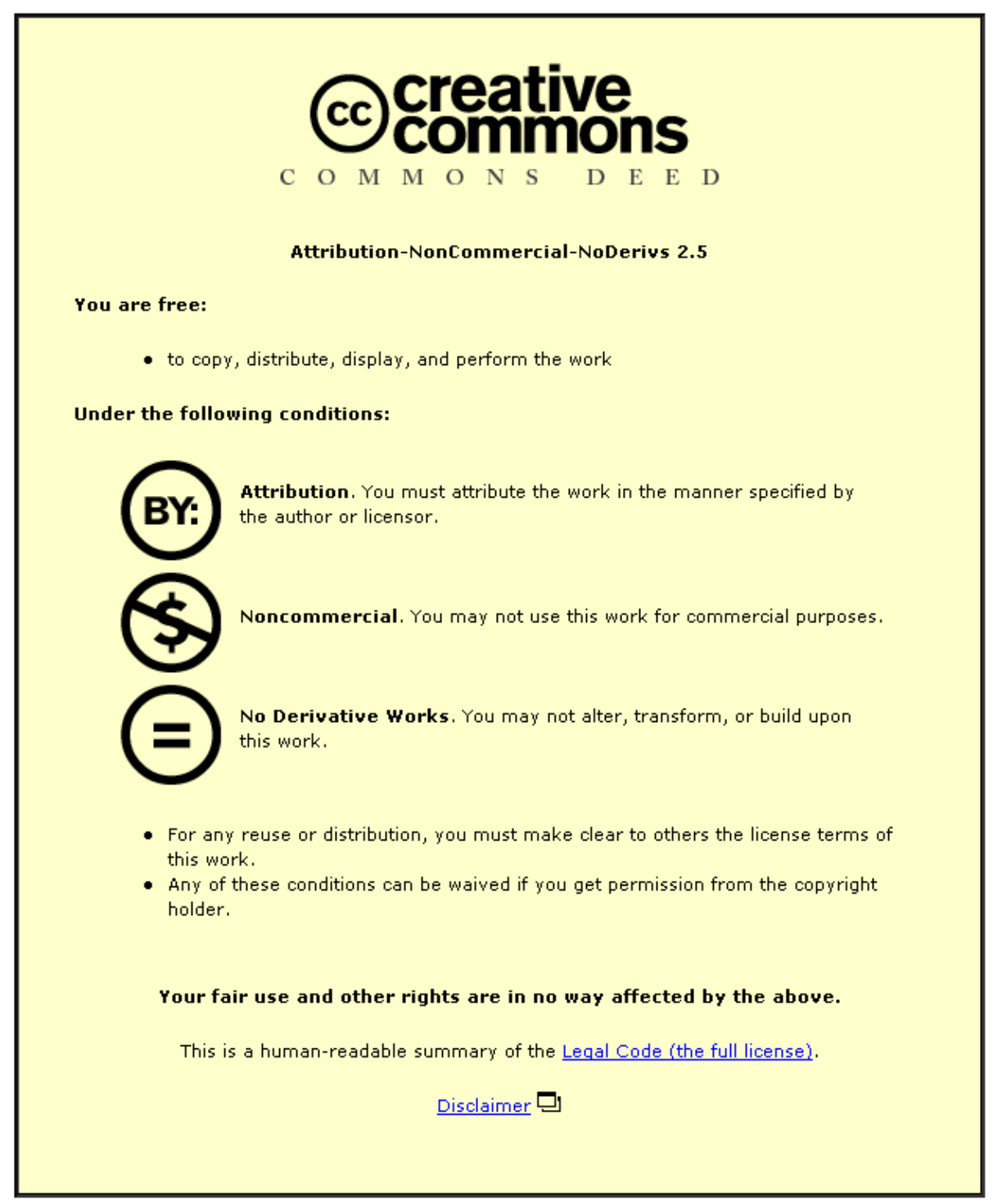

For the full text of this licence, please go to: http://creativecommons.org/licenses/by-nc-nd/2.5/ 
Title: An analysis of climate change policy making and implementation in China

Author(s): Ksenia Chmutina (Research Fellow; School of Civil and Building

Engineering, Loughborough University, UK; Email: K.Chmutina@ lboro.ac.uk)

Jie Zhu (Lecturer, Department of Architecture and Built Environment, Faculty of

Engineering, University of Nottingham, UK; Email: laxjz@nottingham.ac.uk)

Saffa Riffat (Head of Department of Architecture and Built Environment, Faculty of

Engineering, University of Nottingham, UK; Email: Saffa.Riffat@ nottingham.ac.uk).

\begin{abstract}
:
Purpose - This paper introduces and discusses policy making process in the field of climate change in China. The main climate change - related policies are described and the role of China in international climate change negotiations is discussed.

Design/methodology/approach -A qualitative method has been used for this paper. A preliminary desk study based on the analysis of the primary and secondary sources published in both English and Chinese (Mandarin) has been conducted. Literature on policy analysis and evaluation and the role of political actors in it, as well as examples of energy efficiency studies in other countries has been studied to develop an analytical framework for the empirical data interpretation. The main sources for information about China's situation are books, articles, as well as internet resources and newspapers covering China's politics, the climate change regime, and Chinese climate policy.

Findings - The paper provides insights into China's climate change policy making process and outlines the main challenges that policy implementation in China is facing today.

Research limitations/implications - It was appreciated that some sources should be used with caution as information given in Chinese is subject to censorship and governmental control in China and therefore may be biased. It is not possible to avoid this problem totally when dealing with a state like China, but using multiple sources and personal observation may improve the reliability of the information.
\end{abstract}


Practical implications - The paper includes suggestions on policy improvements such as strengthening of supervision mechanisms and creating a Ministry of Energy.

Originality/value - This paper fulfils an identified need to study the climate change policy making process in China.

Key words: China, climate change, policy

Article type: Research paper

\section{Introduction}

China entered a period of high economic growth in 1978. In 2005, the annual economic growth rate was 9.5 and the real GDP had expanded 9.7 times when compared to the GDP in 1980. The growth in energy demand was slower because of energy savings and energy conservation actions due to the measures implemented by Deng Xiaoping (such as demolishing of non-effective small scale coal burners and illegal mines introduced during the Cultural Revolution in order to boost industry performance). However, energy consumption in China is still high and with the dramatic increase in energy demand, China faces serious challenges in the areas of energy security, air pollution, ecological degradation, and climate change. It is difficult to assess the overall impact of climate change on China; however, it can be seen that there is an impact and it is unavoidable (Lu et all, 2006). China spends around 1.5\% of their GDP annually on environmental protection, however, it is estimated that the pollution costs to the Chinese economy is 7-10\% of GDP (Lu et al, 2006).

\section{China's climate change policy}

The traditional concept of harmony in Chinese culture is based on the harmonious relationships between man and nature. Confucianism, Taoism, Legalism and Buddhism all share the idea of "healthy respect for the importance and power of nature to shape mans' conditions". However, the truth is that in China (and not only there), the natural resources have been abused for centuries (Economy, 2004). 
The first discussion on the global level about the environment was introduced to China in 1972 at the UN Conference held in Stockholm on the Human Environment. China's position at the conference was defensive, laying blame for the problems on the developed Western countries. However, China recognised its own environmental problems and in 1973 organised the national conference on environment. The conference concluded that China must pay immediate attention on its environmental problems and subsequently guidelines for environmental protection were set (Heggelund, 2007). Environmental protection became a basic state policy in China in the early 1980s. Since then a large number of laws and regulations have been promulgated. Climate change mitigation is not just a domestic issue; it has a significant impact on the world energy and development situation. China has made great efforts in developing steps towards climate change mitigation and the promotion of energy conservation. It is important to underline that environmental problems lay in the basis of climate-related problems, which energy efficiency issues are a part of.

\subsection{Stages of China's climate change policy}

Harris and $\mathrm{Yu}$ (2005) outline three stages in China's official participation in the climate negotiations: 1990-1992, 1992-1997, and 1997 until now.

Stage 1: Climate change becomes political agenda in China (1980s -1992)

At the end of the 1980s climate change became an important international issue attracting attention of public, media, scientists and governments all over the world (Chayes and Kim 1998 in Bjorkum, 2005). At this stage, China initiated the coordination of its own climate change policy. In 1988, an inter-agency group was established by the Environmental Protection Commission with approval from the State Council; the National Climate Change Coordination Group was formed to facilitate the work of the formulation of China's position for international climate change negotiations (Bjorkum, 2005).

China was also active in participating in international climate change negotiations. During the Intergovernmental Negotiating Committee (INC) negotiations in 1991, China strongly opposed the idea of targets and supported the general framework convention with no specific responsibilities. China was also successful in establishing a unified 
developing countries front in order to resist any singling out of developing countries commitments by the developed countries. From the very beginning of the international negotiations on climate change, China earned the reputation of a 'hard-liner' (Economy 1994 in Bjorkum, 2005). The core elements of China's negotiation position were:

- emphasis on the major scientific uncertainties of climate change;

- focus on protection of national sovereignty;

- historical responsibility of the industrialised countries;

- the transfer of new and additional funding and technologies to developing countries (Hatch, 2003).

China together with other developing countries was able to influence the structure of the Convention, as can be seen in Article 3.1 of the Convention, which calls on the Parties to protect the climate system "on the basis of equity and in accordance with their common but different responsibilities and respective capabilities. Accordingly the developed country Parties should take the lead in combating climate change and the adverse effects thereof" (UN, 1992).

\section{Stage 2: From Rio to Kyoto (1992-1997)}

In 1992, China signed the UNFCCC and then ratified it in 1994. There were six more INC meetings between Rio and the first Conference of the Parties (COP), during which China emphasised that the implementation of the existing commitments should be the COP's major concern and underlined that China was not interested in negotiating until the Annex 1 Parties had implemented all their commitments (Bjorkun, 2005).

When parties gathered in Kyoto for the COP-3, China initially proposed that developed countries should have reduced their emissions of $\mathrm{GHG}^{1}$ to 1990 levels by 2000, and then further by $7.5 \%$ by $2005,15 \%$ by 2010 and $20 \%$ by 2020 , with the total reduction of $35 \%$ by 2020 (Bjorkum, 2005).

In May 1998, China signed, and then in August 2002 ratified, the Kyoto Protocol that came into force on February $16^{\text {th }}, 2005$. At this stage, China's voluntary efforts had thus far been insufficient, especially in terms of implementation and enforcement. In response to the EU concern about the projected rise in its GHG emissions, Chinese

\footnotetext{
${ }^{1} \mathrm{CO}_{2}, \mathrm{CH}_{4}$ and $\mathrm{N}_{2} \mathrm{O}$
} 
officials noted that they could make a concerted effort to place environmental protection at the top of policy agenda. However, China generally was sceptical to Kyoto mechanisms. China and other developing countries objected to Article 17 on emissions trading stating that it would not reduce emissions, and proposed to delete it from the Protocol. In preparation for the implementation of the Kyoto protocol, the government set up an examination council for the Clean Development Mechanism (CDM) and promulgated the Interim Measures for Operation and Management of CDM. When it was first proposed in 1997, the CDM was met with scepticism in China, but received more positive attitude later on because China was able to see the opportunities to improve its energy efficiency and combat local pollution problems. The idea of the Joint Implementation (JI) was also met by China sceptically as China saw this instrument as created primarily for the developed countries benefit, as it helps them to avoid domestic actions (Freestone, 2005).

\section{Stage 3: post- Kyoto China (1997 - currently)}

The main issue during this stage was how to uphold the avoidance of developing countries commitments and how to relate to the Kyoto Mechanisms, especially the CDM (Harris and Yu, 2005).

During the COP-4 meeting in Buenos Aires, China together with India and other developing countries, rejected to the voluntary commitments idea and remarked that developed countries should change the pattern of production and consumption (Heggerlund, 2005). After the next COP-5 meeting in Bonn, China started to discuss the rules and procedures to the practical implementation of CDM projects.

COP-7 agreed on the Marrakech Accord in November 2001. These are seen as the establishment of the CDM Executive Board, the clarification of project cycle and relevant stakeholders, and recognition of Certified Emissions Reduction (CERs) (Lin, 2004).

The CDM mechanism is the most important way for China in UN-led mitigation. The CDM's target is to encourage sustainable development in non-Annex 1 developing countries, and therefore to enable Annex 1 developed countries to invest in emissions reduction projects in non-Annex 1 countries, thus reducing the cost of compliance with 
their commitments. Examples of CDM projects in China are the building of hydroelectric and wind power facilities, destruction or replacement of GHGs in industries, fuel substitution, and waste heat recovery and utilisation in industry. The investing developed countries are issued Certified Emissions Reductions (CERs), which are the credits assisting them in complying with their Kyoto targets; one CER equals one tonne of $\mathrm{CO}_{2}$ equivalent . Currently China is the biggest CDM host with 2,023 out of the 4,869 global projects (Heggelund, 2009).

The following COP meetings were also complex, and until now, there is no agreement on commitments. China did not leave the position it showed during the FCCC and has been very consistent throughout the 15 years of international climate change negotiations. Many targets for 2006 were not met, and as was acknowledged by the Chinese SEPA, the situation with water and air pollution become even worse. China's position on the Kyoto protocol stems from the Chinese government's mutually contradictory policies: maintaining record economic growth and expanding prosperity, and at the same time protecting the environment and preserving social stability. In May 2009, six months before the meeting in Copenhagen, the NDRC issued "The Implementation of the Bali Roadmap: China's Position on the Copenhagen Climate Change Conference" (NDRC, 2009). In this document, China outlines the main principles of the UNFCCC and its Kyoto Protocol, and gives the objectives of the Copenhagen Climate Change Conference. It also emphasised in the Roadmap that it is important to enhance the "full, effective, and sustained implementation of the UNFCCC" by the means of cooperation, mitigation, adaptation, technology development and transfer and financial support. The last section of the document states that the developed countries should further quantify their emissions reduction commitments (with the reduction of at least $40 \%$ below their 1990 level by 2020).

Just before the actual COP-17 meeting in December 2009, China announced its emissions cut target: "China will cut $\mathrm{CO}_{2}$ emissions per unit of GDP by 40-45\% by 2020 from the 2005 level, increase the share of non-fossil fuels in primary energy consumption to around $15 \%$ by 2020, and increase forest coverage by $40 \mathrm{mln}$ hectares and forest stock volume by 1.3 bln $\mathrm{m}^{3}$ by 2020 from the 2005 levels (BBC News Nov 26, 2009). As can be seen, China's reduction is measured in carbon intensity, which differs 
from the traditional measurement of the emissions in tonnes. The meeting in Copenhagen was very controversial for China, and China was blamed by many governments for the failures of the meeting. As the summit did not achieve the results planned, there is still need for more negotiations on legally binding final agreements.

\subsection{Strategies for addressing climate change}

Addressing climate change is a very important part of China's policy making process. In doing this, China sticks to the following principles:

- Context of sustainable development: China's development should achieve a winwin outcome of pursuing economic development and addressing climate change.

- Common but different responsibilities: this is the core principle of the UNFCCC, according to which both developed and developing countries must adopt measures to mitigate and adapt to climate change, but due to the historical responsibility, developed countries should take a lead in reducing emissions.

- Equal emphasis on both mitigation and adaptation; these are the integral components of coping with climate change, and both must be treated with equal importance.

- $\quad$ The UNFCCC and Kyoto Protocol are the main channels for addressing climate change.

- $\quad$ Relying on science and technology innovation and technology transfer.

- $\quad$ Relying on public participation and international cooperation: dealing with climate change requires the participation of the whole society, as this is a challenge faced by the entire world (SC, 2008).

\section{Current climate change related laws and regulations}

Today, there are three categories of China's policies on the topic related to climate change mitigation: China's Central Government established the first two levels, and local governments (provincial, municipal, and county) established the third level with overall direction from the first two levels. The first level policies provide general directions and guidance; they also include country leaders' speeches and government standpoints on the global environment and development of renewable energy. The 
second level policies specify aims and development plans mostly with the focus on rural electrification, renewable-energy generation technology and fuel wood. The aim of these policies is to standardise the directions, focal points, and objectives of renewable energy development from different viewpoints. The third level policies include practical and specific incentives and managerial guidelines, and specific supporting measures for developing and using renewable energy (Christiansen, 1996).

China has a very large state apparatus with the complex division of labour and responsibilities. In the 1990s, China saw climate change as a matter of science rather than energy, economy, and politics. Climate change issues were the responsibility of the CMA and other scientific agencies. However, gradually, climate change issues have shifted from being just science issues to being political and economic issues, and then they became the responsibility of the NDRC (Zhou, 2009). This section outlines the central actors in Chinese climate change policy-making:

- The National Coordination Committee on Climate Change (NCCCC) was established in 1990 with the aim of promoting coordination among various relevant ministries and governmental bodies on climate change. The Climate Change Office functions as the secretariat to the NCCCC and practically has the responsibility for climate work in China. Different officials in the Office are responsible for the CDM, the Asia-Pacific Partnership (APP) for Clean Development and Climate, etc (Heggelund, 2007). All the following ministries are the members of NCCCC.

- The National Development and Reform Commission (NDRC), who's highest priority is to maximize economic development and rapid expansion of energy suppliers, acts as a coordinator of China's climate change activities. The Department of Foreign Affairs deals with the cooperation between the NDRC and international organisations, foreign government agencies and foreign institutions, including investors.

- The Ministry of Foreign Affairs (MOFA) that has its leading role in international political negotiations on climate change. It is the second important actor in climate change policy making, as it is seen in China as an international issue. The MOFA usually is a head of the climate change negotiations, though it is less involved in scientific and technical aspects (Heggelund, 2007). 
- The Ministry of Environment Protection (MEP) (also known as the State of Environmental Protection Administration (SEPA)) being the main administration in charge of environmental policy-making and implementation, can also be characterised as a weak bureaucratic agency, facing constant challenges to its authority by the Ministry of Forestry, the Ministry of Energy, the Ministry of Agriculture and State reform Commission (SRC); however it plays an important role on the international arena. It is responsible for environmental protection including drawing up international principles on global environmental issues, administering international cooperation on the environment, and participation and coordination of important international environmental events (Ho and Vermeer, 2006).

- The China Meteorological Administration (CMA) works to develop China's scientific capacity for climate monitoring and modelling, both through domestic support and international funding.

- The Ministry of Science and Technology (MST) deals with the technical aspects of China's climate change mitigation programme, it is highly involved in technological transfer and scientific research. It also plays a crucial role in China's CDM participation; it has the broadest technical expertise about CDM in China and plays an important role in the development of CDM projects (Heggelund, 2007).

Other important bodies are the Ministry of Finance (MOF), the Ministry of Agriculture, the Ministry of Water resources, and the State Forestry Administration. China does not have a separate energy ministry, though its establishment is currently being discussed mainly because such a ministry with clear mandate and authority can achieve efficient implementation of energy policy. Currently, an Office of the National Energy Leading Group established in 2005 and working under the NDRC is in charge of overall energy strategy, however its functions are not totally clear (Heggelund, 2007).

As can be seen, there are several ministries involved in the process of formulating China's position on climate change, and they all have a different degree of influence. The structure of these actors lacks a framework that would be able to provide the delegation of responsibilities among the numerous governmental bodies and institutions. All these actors are engaged not only in climate change policy-making but also in other policy areas, such as energy planning, economic development, China's foreign policy 
etc. The Chinese government expects these actors to endorse a proactive climate policy choice only to the extent that it does not conflict with that particular sector's other goals with higher priorities (Bjorkum, 2005).

The Chinese government also involves scientists in the process of decision-making, and they have been involved in different projects for several years now. Recently, twentyeight Chinese experts were elected for the writing-up of the forth assessment report of the IPCC; Chinese scientists are also included into the COPs with their expertise increasingly aiding the negotiations. Economists from CAS, Qinghua University and Renming University have also been involved in climate change related work and been part of China's delegations to climate negotiations. These actors with different backgrounds are extremely important for China's policy-making process; however it is difficult to assess the influence that they have on the climate change arena (Heggelund, 2007).

Increasingly, information and knowledge are becoming more and more important as the basis for the policy making process. This means the information provided by research institutes, academies, agencies, and other think tanks. These think tanks can be independent bodies, as well as subordinate to commissions or ministries; however again, it is impossible to assess if they have the greatest influence on a climate change policy making process (Heggelund, 2007). China has significantly increased its total R\&D spending and it currently stands at $1.5 \%$ of GDP, which is about 40 bln USD. China has a great stock of human resources for science and technology and plans to spend $2.5 \%$ of GDP on R\&D by 2020 (Bosetti et al., 2009).

Although China has made good progress in achieving some of their policy targets, there are still many factors contributing to the poor performance of others.

The most significant factors affecting policy performance are (ADB, 2007):

- Inadequate attention of local government to environmental protection: under the Chinese administrative system, local governments are in charge of regulations, management, and protection. However the funding for environmental and climate change related policy implementation tends to be underprovided or not provided at all. There are also many cases where project approvals were granted in violation of environmental law enforcement. The main problem has been that the local government 
can be a shareholder if not an owner of the enterprises that it is supposed to be regulating. As a result of this factor, the second factor appears.

- Ineffective regulatory framework and weak supervision and enforcement: though there are various laws, regulations and standards that have been enforced in the past 5 years, many of them are adopted from foreign countries without proper regard to the Chinese system. Some of the regulations lack enforceability; also there are often loopholes in them, as often the local government is responsible for the construction project as well as its monitoring and supervision. This often happens especially on a local level in small and medium cities. Moreover, most of the economic charges are too low, so it can make more economic sense to pay the charge.

- Overheated economy: when, between 2000 and 2002, the structural adjustments were implemented into the energy sector, the energy consumption decreased, however by 2003 the economy started to grow again with the high energy-consumption sectors growing by $10 \%$ throughout the year. The government has to pay more attention to creating institutional and regulatory levels with which it can influence economic development.

- Lack of cross-sectoral coordination: environmental and climate change related issues are responsibilities shared between multiple agencies, therefore, under such an arrangement, strong cross-sectoral coordination is crucial. The lack of it is possibly the main factor contributing to the non-achievement of targets.

\section{Main governmental policies}

Energy policies are the most important in climate-related policies in China: they are central for the economic growth, and at the same time, energy in China is the main source of GHG emissions. China has implemented different measures in order to improve energy efficiency and decrease energy intensity (Richerzhagen and Scholz, 2007).

Agenda 21 
In 1993, the Chinese Government took part in the Global Environment and Development Conference of the UN, after which the path towards development and utilization of clean energy was taken (Andrews-Speed, 2009). It was emphasised again in the "Agenda 21 of China" to develop new and renewable energy. In 1995, the "Electricity Act of the People's Republic of China" was issued. This Act was the first to deal with energy resources: it showed that the Government encourages and supports the use of clean and renewable energy resources for electricity generation, and it emphasised the importance of developing and using renewable energy resources in construction of rural power generating capacity and agricultural power consumption (Heggelund, 2007).

\section{Energy Conservation Law}

The Energy Conservation Law of the PRC came into effect in January 1998. It includes six chapters covering general provisions, energy conservation management, rational utilisation of energy, technological progress of energy conservation and legal liability. The Law states that governmental authorities at all levels are requested to give investments for energy saving purposes and must strengthen the management for energy-using entities consuming over 7,000 tce annually. It also gives a list of energy efficient technologies and stipulates the measures in case of non-compliance, such as revoking a business licence (NDRC, 1998).

Currently a new Energy Law is to be enforced. A consultation process on its draft has been closed and presented to the Office of Law of the State Council and then will be submitted to the NPC for approval. This law is to be a basic law to guide and coordinate other laws in China's energy sector. It covers coal, oil, natural gas, renewable energy and nuclear energy as well as electricity, thermal power and petroleum products. This new law is planned to overlay specific energy laws, such as the Renewable Energy Law, Energy Conservation Law and the Electric Power Law and actions and measures associated with them. The purpose of the Law is to standardise the development, use and administration of energy; create a sustainable energy supply and service system; increase energy efficiency and security; promote the development and renewables of awareness of society in general (Energy Group, 2008). 


\section{Five-Year Plans}

In March 1996, the $4^{\text {th }}$ session of the $8^{\text {th }}$ Congress of NPC adopted the outlines of the $9^{\text {th }}$ Five-year Plan and long-term target till 2010. Sustainable development was introduced as an important strategy for the modernisation drive. Electricity generation was to be increased with coal as a primary source, but the exportation of petroleum and natural gas reserves and development of new energy resources were also to be encouraged. The importance of small hydro, wind, solar, geothermal, and biomass power were mentioned as well (NDRC, 1996).

The $11^{\text {th }}$ Five-year Plan was approved by the $5^{\text {th }}$ Plenary Session of the $16^{\text {th }}$ NPC in 2006 (NDRC 2006). It sets energy conservation targets for local governments and key central government departments. It also sets specific energy targets for electricity generation, some industrial processes, appliances, and transport. It contains a number of different measures that are designed to increase the share of renewable energy in China's energy portfolio (Zhou et al., 2009).

\section{National Climate Change Programme:}

The National Climate Change Programme was implemented in 2007. It outlines the impact of climate change on China, and sets out a strategy to mitigate climate change and achieve sustainable development. This includes economic restructuring, energy efficiency improvement, vehicle emissions standards, participation in international $R \& D$ programmes, development, and utilisation of renewable energy etc. Many of these targets are from the $11^{\text {th }}$ Five-year Plan (2006-2010) (NDRC, 2007).

The main objectives of the Programme are:

- To control GHG emissions and to enhance the capacity of adaptation to climate change by accelerating the transformation of their economic development pattern, strengthening policy on energy conservation and utilisation, speeding up R\&D and enhancing public awareness. This also involves the optimisation of energy consumption through the development of renewable energy and nuclear power; the reinforcement of their industrial policies concerning metallurgy, construction materials and the chemical industry; control irrigation and fertilisation systems, and water conservation; increase forest coverage; monitor the trend of sea-level variation, etc. 
- To enhance R\&D by strengthening, further developing and improving basic research on climate change, and building up independent innovation capacity and promoting international cooperation and knowledge transfer.

- To raise public awareness and improve management by promoting more publicity, education and training; improving the inter-ministerial decision-making mechanism and developing a new mechanism, which would involve public participation.

For all the objectives to be addressed, the Programme suggests key areas that have to be a matter of priority. It also suggests major steps to aid mitigating climate change for each area. It mentions the key areas that have to adapt to climate change and emphasises the need for international cooperation (NDRC, 2007).

\section{International cooperation}

Since the 1980s, China has joined many international organisations and signed several international treaties. China's role in international politics and cooperation has increased dramatically since then. There are many forces that drive China to be more active in international carbon cooperation including scientific knowledge and political consensus; international regime enhancement; information sharing and public awareness; difference

of technologies and their costs; trade liberalisation; TNCs expansion; and the issue of China's image (Research Centre for Sustainable Development, 2006).

One of the ways in which China is showing its international cooperation on climate change mitigation is in the short term by coping with climate change through enhancing carbon management and improving energy efficiency, and in the long-term by reducing the GHGs and mitigating future climate change through financing the development of low carbon technologies. By no means, international cooperation always brings China benefits (Johnson, 2001).

China, being one of the major contributors as well as one of the potential victims of climate change, has become one of the main recipients of climate-related aid from bilateral and multilateral cooperation projects from the World Bank, the UNDP, the ADB, and others (RCSD, 2006). Moreover, China gets a lot of financial support from bilateral cooperation projects on climate change with the USA, Canada, Australia, 
Switzerland, and Norway. The largest bilateral projects are: EU-China Energy and Environment Partnership; Fossil Energy Protocol between the USA and China; and Climate Change Partnership of Australia and China.

Another important cooperation in the area of climate change is China - UN cooperation. China took its seat in the UN in 1971, and now undertakes a very important role in representing developing countries in the UN. The UNEP was established in the 1970s, and has had good relationships with China ever since. China has established foreign missions in the UNEP after the Stockholm conference, and the UNEP is playing an important role in establishing environmental institutions in China. It also contributes to strengthening SEPA's position within the Chinese government. The following are the main important points in China-UN cooperation (Heggelund, 2007): training of personnel and policy making; public awareness; technical assistance; networking.

China also receives $17 \%$ of the total funding for climate change projects from the Global Emission Facility (GEF), 70\% of which is used on energy efficiency projects and renewable energy projects, etc. In 2002 CDM projects were established in China; from 2002 to 2005 the total foreign investment for the development of 4 CDM projectsin China accounted for approximately 7.73 bln RMB (US \$ 0.93 bln) (RCSD, 2006).

China can be characterised as a key actor in climate change discussions and negotiations as it has an influential position in the "Group of 77 and China". It is a rather heterogeneous group with largely different interests but acting united in climate change negotiations. China plays a major role in forming the position of the developing countries in these negotiations: this position being that it was the developed countries who played the largest part in emitting the GHG emissions that have caused the problems that the world is facing now; moreover, developed countries' technological and technical capacity to reduce emissions and mitigate climate change is much better then developing countries (Bjorkum, 2005).

It is important to remember that China is sceptical of international regimes to some extent. The country is cautious towards any policies that might affect its national sovereignty or questions that concern internal affairs of state (Heggelund, 2007).

\subsection{Multilateral agreements}

The Asia-Pacific Partnership (APP) on Clean Development and Climate 
The APP is one of the climate change mitigation initiatives working outside of the UN. It is a pact of seven countries with the aim to reduce emissions though technology and voluntary public-private partnership (Heggelund, 2009). The APP countries are working with China in carbon-associated areas, and this has proved successful. Some APP projects involve multilateral banks in order to finance APP the programmes identified by the task forces, such as expand the use of technologies and practices designed to promote objectives of the Partnership (RCSD, 2006).

In 2006, the APP issued its communiqué outlining that the "Partnership will be consistent with and contribute to our efforts under the UNFCCC and will compliment, but not replace, the Kyoto Protocol” (APP, 2006). The APP has established main tasks forces that will focus on: renewable energy and distribution generation, power generation and transmission, and reducing energy consumption in the following industries: steel, aluminium, cement, coal mining, and building and appliance. There are also five projects listed as 'cross-cutting or other'. China is involved in all task forces, but not all projects, and is a co-chair of the Cleaner Fossil Energy Task Force and the Power Generation and Transmission Task Force (APP, 2009).

There are a number of factors that explain why China is highly involved in the APP. The main motivation is the potential for the APP to contribute to China's energy security challenges as all task forces are related to energy production, energy intensive industries, or energy efficiency. Secondly, the APP focuses on technology that coincides with Chinese goals. Thirdly, the APP countries would like to mitigate climate change without giving up their development growth, which is very attractive to China. Fourthly, the APP provides a way for China to position itself on the global arena (Heggelund, 2009).

\subsection{Bilateral agreements}

The UK - China Action Plan on Climate Change and Energy

"The UK - China Action Plan on Climate Change and Energy" was outlined in December 2007. Its main objectives are to "ensure climate security and secure, clean energy supplies at affordable prices by promoting a faster transition to a low carbon economy in China, and China's role in delivering an international framework" (IEA, 
2008). This main target is made of seven objectives that are: encouraging China to engage positively in international negotiations; ,raising awareness and understanding of the need to adapt to climate change; persuading key national and regional political and industrial policy-makers and leaders of the need to address climate change; accelerating the delivery of key technology cooperation projects, including the Near Zero Coal Emissions project; persuading China to borrow for clean energy projects from the World Bank and the ADB, and to maximise its opportunities under the Environmental Transformation Fund; strengthening China's performance on improving energy efficiency; strengthening China's ability to better forecast future energy demand.

\section{Conclusions}

Energy conservation and energy saving is one of the priority areas for Chinese government. There is already evidence that some of the governmental actions are having an effect. However, the main problem here is whether China will be able to stick to its commitments and not make their economic development a greater priority, above energy efficiency.

One commission and two ministries have become more involved with climate change think tanks and there is a trend that the number of actors in the policy making process will be increased. The policy making process in extremely complex in China and the agencies in charge do not always communicate well, which makes policies and regulation less efficient than they could be.

Climate-related and environmental aspects are now an integral part of China's FiveYear programmes, however, most of the policies are based on the desire to keep up with the economic growth and maintain it. Often the targets set are too ambitious, and sometimes the targets are a desirable by-product but not the main objective. China has the capacity to develop climate-related measures, and it has been proven already. However, lack of enforcement and monitoring tools is a very big issue that needs to be overcome.

China actively participates in international efforts on climate change mitigation and takes part in multilateral, regional, and bilateral cooperation. However, China's principle 
position has not changed dramatically, and it is unlikely that the major policies will be reviewed is the near future.

\section{References}

Andrews-Speed, P. (2009). China's ongoing energy efficiency drive: origins, progress and prospects. Energy Policy, 37, p. 1331-44.

APP (n.d). APP project roster. Available at:

http://www.asiapacificpartnership.org/english/project_roster.aspx (accessed at 1/12/09)

APP (2009). Communiqué from the Asia-Pacific partnership on clean development and climate inaugural ministerial meeting. Shanghai, China. Available at: http://www.asiapacificpartnership.org/Communique.pdf (accessed on 1/12/09).

Asian Development Bank (2007). Country Environmental Analysis for the PRC. Available from http://www.adb.org/Documents/Produced-Under-TA/39079/39079PRC-DPTA.pdf (accessed on 2/12/09).

BBC News (2009). China unveils emissions targets ahead of Copenhagen. BBC News Online, 26 November. Available at http://news.bbc.co.uk/1/hi/8380106.stm (accessed on Jan 23, 2010).

Bjorkum, I. (2005). China in the International Politics of Climate Change: A Foreign Policy Analysis (FNI Report 12/2005). Available at: http://www.fni.no/doc\&pdf/FNIR1205.pdf (accessed on 6/04 2008).

Bosetti, V.; Tavoni, M., \& Carraro, C. (2009). Climate Change mitigation strategies in fast-growing countries: The benefits of early action. Energy Economics, 31, p. 144-51.

Christiansen, F. (1996). Chinese Politics and Society: an introduction. UK: Pearson Education Ltd.

Economy, E. (2004). China vs. Earth. The Nation. Available at: www.thenation.com/doc/20070507/economy (accessed on 1/12/2009). 
Freestone, D., \& Streck, C., eds. (2005). Legal Aspects of Implementing the Kyoto Protocol Mechanism: Making Kyoto Work. Oxford: Oxford University Press.

Harris, P., \& Yu, H. (2005). Environmental change and the Asia Pacific: China responds to global warming. Global change, Pease and Security, 17(1), pp. 45-58.

Hatch, M.T. (2003). Chinese politics, energy policy, and the international climate change negotiations. In P.G. Harris, ed. Global warming and East Asia; the domestic and international politics of climate change. London and NY: Routledge, pp. 43-65.

Heggelund, G. (2007). China's climate change policy; domestic and international developments. Asian perspective, 31 (2), p. 155-91.

Heggelund, G. (2005). International CER market and CD experiences in developing countries (final report). CPR/01/002 and CPR/02/H02 Building Capacity for the CD in China, FNI.

Heggelung, G., \& Buan, I.F. (2009). China in the Asia -Pacific Partnership: Consequences for UN Climate Change Mitigation Efforts?. International Environmental Agreements, 9(3), p. 301-17.

Ho, P., \& Vermeer, E.B. (2006). China's Limits to growth: greening state and society. Oxford: Blackwell Publishers.

International Energy Agency (2008). China energy database. Available at www.iea.org (accessed on 14/12/2008).

Johnson, T.M. (2001). Foreign Involvement in China's Energy Sector. In E. Economy \& M. Oksenberg, eds. China joins the world. NY: Council of Foreign Relations Press.

Lin, W.; Heggelund, G.; Yangen, K., \& Feng, L.J. (2004). Efficient implementation of CDM in China. Report prepared for Norwegian Ministry of Foreign Affairs. Beijing.

Lu, X.; Pan, J., \& Chen, Y. (2006). Sustaining economic growth in China under energy and climate security constrains. China and World Economy, 14 (6), p. 85-97. 
NDRC (1996). $9^{\text {th }}$ Five-Year Plan. Beijing. Available at: http://www.ndrc.gov.cn/ (in Chinese) (accessed on 14/06/10).

NDRC (2006). $11^{\text {th }}$ Five-Year Plan. Beijing. Available at: http://www.ndrc.gov.cn/ (in Chinese) (accessed on 14/06/10).

NDRC (1998). China's energy Conservation Law. Available at: http://www.unescap.org/esd/energy/publications/compend/ceccpart4chapter4.htm (accessed on 14/06/10).

NDRC (2007). China's National Climate Change Programme. Beijing.

NDRC (2009). Implementation of the Bali Roadmap, May 20. Available at: http://en.ndrc.cn/newsrelease/t20090521_280382.htm (accessed on 23/01/10).

Research Centre for Sustainable Development (2006). Understanding China's Energy Policy. Chinese Academy of Social Science, Beijing.

Richerzhagen, C., \& Scholz, I. (2007). China's capacities for mitigating climate change (Discussion paper). German development Institute. Available at: http://www.diegdi.de/CMS-Homepage/openwebcms3.nsf/(ynDK_contentByKey)/ADMR-

7BRFAV/\$FILE/ScholzRicharzhagen22-2007.pdf (accessed on 24/06/2010)

State Council of the PRC (2008). China's policies and actions for addressing climate change, State Council Information Office, Beijing.

United Nations (1992). UN Framework convention on climate change. Available at http://unfccc.int/resource/docs/convkp/conveng.pdg (accessed on 1/12/2009).

United Nations (1997). Kyoto Protocol. Available at: http://unfccc.int/kyoto_protocol/items/2830.php (accessed on 12/12/2007).

Wara, M. (2008). Measuring the clean development mechanism's performance and potential. UCLA Law Review, 55, p. 759-1803. 
Zhou, N., Levine, M.D., \& Price, L. (2009). Overview of current energy efficiency policies in China. Energy policy, 10.

Bio:

Dr Ksenia Chmutina is a Research Associate at the Loughborough University and currently works on CLUES project. Ksenia has a multidisciplinary background in building energy efficiency ( $\mathrm{PhD}$ at the University of Nottingham), Media studies (MA at the University of Nottingham, China) and International Relations and Politics (Amur State University, Russia).Her PhD project focused on the analysis of the effectiveness of energy efficiency standards for commercial buildings in China. Her research interests are mainly on evaluation of energy efficiency policies and regulations, but also on buildings energy efficiency and energy systems.

Dr Zhu Jie is a lecturer at the Institute of Sustainable Energy Technology, Univeristy of Nottingham. He has a high level of expertise in applied thermodynamics, heat transfer, refrigeration, heat pumps, sustainable/renewable energy technologies and energy efficiency technology. Dr Zhu has been involved in a number of research projects on energy efficiency, vapour compression, desiccant refrigeration, evaporative cooling, ejector air conditioning and energy storage systems, and has published over 30 scientific papers in refereed journals and conferences. He is currently investigating building energy and sustainability. Dr Zhu also has two years of industrial experience with a manufacturer of air conditioners and heat pump systems.

Prof Saffa Rifftat is the Head of the Department of Architecture and Built Environment, University of Nottingham and the Head of the Institute of Building Technology \& Institute of Sustainable Energy. 